\title{
PENAMAAN DESA DI KABUPATEN BANYUASIN DALAM PERSEPSI TOPONIMI TERESTRIAL
}

\author{
Rahmat Muhidin \\ Balai Bahasa Sumatera Selatan \\ Jalan Seniman Amri Yahya, SU I, Jakabaring, Kota Palembang \\ Email: rahmatmuhidin005@gmail.com
}

\begin{abstract}
Abstrak
Penelitian ini bertujuan untuk mendeskripsikan penamaan desa di Kabupaten Banyuasin berdasarkan kajian toponimi terestrial. Penelitian ini menggunakan metode deskriptif. Hasil kajian penamaan nama desa di Kabupaten Banyuasin dapat dideskripsikan sebagai berikut. penamaan desa di Kabupaten Banyuasin berdasarkan persepsi toponimi terestrial mengacu pada sumber daya alam terestrial dan sumber daya marine (maritim). Penamaan desa cenderung mengacu pada (1) nama desa yang berasal dari nama orang; (2) nama desa yang berasal dari nama tumbuhan; (3) nama desa yang berasal dari unsur nama geografis a) karang, b) kebon, c) kuala, d) lalang, e) muara, f) pulau, g) rantau, h) rawa, i) rimba, j) tanah, k) talang, l) telang, m) sungai, n)upang, o) tebing, p) teluk, q) nama yang berasal dari nama tanjung, r) nama desa yang berasal dari nama pematang, s) nama desa yang berhubungan dengan pangkalan, t) nama desa yang menggunakan kata lubuk, u) nama desa yang berhubungan dengan harapan merupakan penamaan desa yang mengacu pada bentuk atau wujud desa yang berhubungan dengan harapan.
\end{abstract}

Kata kunci: penamaan, toponimi, terestrial

\section{Abstract}

This study aims to describe the naming of villages in Banyuasin Regency based on terrestrial toponymy studies. This research uses a descriptive method. The results of the study of naming villages in Banyuasin Regency can be described as follows. the naming of villages in Banyuasin Regency based on the perception of terrestrial toponymy refers to terrestrial natural resources and marine (maritime) resources. Village naming tends to refer to (1) the name of the village that comes from the name of the person; (2) the name of the village derived from the name of the plant; (3) the name of the village that comes from the elements of a geographical name a) coral, b) kebon, c) kuala, d) lalang, e) estuary, f) island, g) rantau, h) swamp, i) jungle, j) land , k) gutters, 1) telang, m) rivers, n) upang, o) cliffs, p) bays, q) names originating from the name of the cape, r) village names derived from dike names, s) related village names with base, t) the name of the village that uses the word lubuk, $u$ ) the name of the village that relates to hope is the naming of the village that refers to the shape or form of the village that is related to hope.

Keywords: naming, toponymy, terestrial

\section{PENDAHULUAN}

Manusia bertempat tinggal di suatu wilayah tertentu memiliki tujuan dan maksud yang jelas. Seperti halnya manusia mendiami suatu wilayah di muka bumi, maka manusia akan memberi nama kepada semua unsur-unsur geografi, seperti nama untuk sungai, bukit, gunung, lembah, pulau, teluk, laut, selat, dan sebagainya yang berada di wilayahnya. Bahkan manusia memberi nama pada daerah yang ditempatinya, seperti nama permukiman (nama real estat), nama desa, nama kampung, nama huta atau nagari dan seterusnya sampai dengan nama-nama kota. Tujuan memberi nama pada unsur geografi adalah untuk identifikasi atau acuan dan sebagai sarana komunikasi antarsesama manusia. Dengan nama-nama unsur geografi sangat terkait dengan sejarah pemukiman manusia.

Nama unsur geografi atau disingkat nama geografik (geographical names) disebut toponim. Secara harafiah, bermakna nama tempat atau place names. Nama tempat tidak harus diartikan nama pemukiman/nama tempat tinggal, tetapi nama unsur geografi yang ada di suatu tempat (daerah), seperti sungai, bukit, gunung, pulau, tanjung dan sebagainya. Unsur-unsur ini dikenal secara luas sebagai unsur topografi "the physical features on an area of land, such as rivers, mountains, islands, seas, etc dalam Oxford 
Advances Learner's Dictionary 2000). Manusia yang bermukim pertama kali di suatu wilayah tentunya memberi nama pada unsur-unsur geografik di lingkungannya. Nama diberikan berdasarkan apa yang dilihatnya, seperti pohonpohonan atau buah-buahan yang dominan di daerah itu, contoh: Kampung Rambutan, Pulau Pisang, Pulau Bangka dan sebagainya. Nama juga bisa berasal dari nama binatang yang dijumpai atau menghuni tempat itu, seperti Pulau Kambing, Pulau Menjangan, Pulau Merpati, Pulau Burung, dan lainnya. Banyak nama geografik diciptakan dari dari legenda rakyat seperti legenda Sangkuriang untuk gunung Tangkubanperahu di Jawa Barat dan gunung Batok di Jawa Timur. Di sisi lain, ada legenda di Pasifik Selatan. Begitu juga dengan legenda si Malin Kundang, tidak khas Sumatera Barat, juga ada di Riau Kepulauan, Kalimantan Selatan dan legenda yang sama terdapat di Pasifik Selatan. Dengan kata lain, ada penduduk dari suku-suku di Pasifik Selatan (Polinesia) yang mengembara di kepulauan Indonesia di zaman prasejarah. Seperti halnya kata bukit di Indonesia berasal dari kata Puke dalam bahasa Polinesia menjadi Phuket di Thailand, buket di Malaysia. Salah satu tempat di Pasifik ada nama pulau Puke Rua artinya pulau Bukit Dua (Prof. Dr. Yacub Rais: Arti Penting Penamaan Unsur Geografi Definis, Kriteria dan Peranan PBB dalam Toponimi (Makalah Seminar Bakorsurtanal, 2005).

Berdasarkan paparan pada latar belakang di atas, maka rumusan dalam penelitian ini adalah sebagai berikut:

(1) Mengapa masyarakat Kabupaten dalam menamai suatu wilayah seperti kampung atau desa berkaitan dengan pengalaman empiris yang dialaminya?

(2) Apa sajakah yang melatarbelakangi pola pikir masyarakat Kabupaten Banyuasin dalam menamai desa di lingkungannya?

Berdasarkan rumusan masalah dalam penelitian ini, penelitian ini bertujuan untuk:

(1) Mendeskripsikan penamaan nama desa oleh masyarakat Kabupaten Banyuasin dalam menamai suatu desa dan menghubungkannya dengan pengalaman masyarakat Kabupaten Banyuasin di masa lalu yang sangat berharga. Selain itu sebagai sarana mewujudkan kearifan lokal yang diabadikan dalam suatu penamaan desa di Kota Kabupaten Banyuasin
(2) memaparkan hal-hal yang melatarbelakangi pola pikir masyarakat Banyuasin dalam menamai desa di Kabupaten Banyuasin.

Mengacu pada pendapat Boas, menyebutkan bahwa pendeskripsian terhadap suatu bahasa hendaknya didasarkan pada apa yang ada di dalam bahasa itu sendiri (di dalamnya berdasarkan budaya dan pandangan hidup), bukan berdasarkan pada tata bahasa lain. Pengertian tersebut juga didukung oleh pendapat Troike (1990:1) mengenai etnografi bahwa ethnography is a field of study which concerned primarily with the description and analysis of culture, and linguistics is a field concerned, among other things, with the description and analysis of language code. Pendapat lain mengenai Etnolinguistik juga dikemukakan oleh Duranti (1997:2) bahwa etnolinguistik adalah kajian bahasa dan budaya yang merupakan subbidang utama dari antropologi (ethnolinguistics is part of a conscious attempt at consolidating and redefining the studi of language and culture as one of the major subfield of anthropology). Lebih lanjut dijelaskan bahwa etnolinguistics is the study. of speech and language within the context of anthropology. Berdasarkan pengertian di atas dapat disimpulkan bahwa etnolinguistik merupakan studi linguistik yang menyelidiki bahasa kaitannya dengan budaya suku bangsa di manapun berada. Kajian etnolinguistik tidak terbatas pada suku bangsa yang tidak mempunyai tulisan tetapi yang sudah mempunyai tulisan pun dapat dikaji. Spradley (dalam Elizabeth, 1997:140) berpendapat bahwa setiap bahasa mempunyai banyak istilah penduduk asli yang digunakan oleh masyarakat untuk merujuk hal-hal yang mereka alami dan nama benda yang ada di sekitar mereka.

\section{LANDASAN TEORI}

Nama juga merupakan bagian integral dari sosok manusia dan kehidupan manusia. Nama dapat dikaji dan ditelisik oleh Onomastics atau Onomatology dalam salah satu cabang ilmu bahasa yaitu Historical Linguistics. Onomastik khusus mengkaji mengenai asal usul nama diri maupun nama tempat. Kajian yang berkaitan nama diri dinamakan Antroponimi, sedangkan kajian yang berhubungan dengan nama tempat disebut toponimi. Onomastika (onomastics, onomasiology) merupakan penyelidikan tentang asal-usul bentuk dan makna nama diri, terutama nama orang dan tempat (Kridalaksana, 1993:149). 
Nama merupakan hal yang sangat penting dalam kehidupan manusia, baik nama diri maupun nama tempat. Nama juga diperlukan untuk berkomunikasi dan menyampaikan informasi kepada orang lain.

Toponimi atau nama tempat merupakan nama yang diberikan kepada unsur rupabumi yang tidak hanya berupa tulisan di peta atau papan nama petunjuk jalan atau lokasi suatu tempat. Lebih jauh, toponimi/toponim merupakan informasi geospasial yang berfungsi sebagai titik akses langsung dan intuitif terhadap sebuah sumber informasi lainnya. Toponimi merupakan ilmu yang mempelajari nama tempat (toponim), mulai dari asal usul, arti, makna, penggunaan dan tipologinya. Kajian toponimi sangat erat kaitannya dengan bidang ilmu lain terutama pemetaan, kartografi, antropologi, geografi, sejarah dan kebudayaan.

Penamaan tempat dalam perkembangannya dewasa ini jika dikaitkan dengan tujuan pembakuan nama rupabumi cukup memprihatinkan. Ini karena banyak digunakannya bahasa asing untuk nama tempat yang menyebabkan lunturnya budaya bangsa dan tersingkirnya bahasa daerah dan bahasa Indonesia. Padahal, UU RI No. 24 Tahun 2009 tentang bendera, bahasa, lambang negara, serta lagu kebangsaan pada Pasal 36 mengamanatkan bahwa Bahasa Indonesia wajib digunakan dalam nama geografi di Indonesia dan penamaan yang dimaksud dapat menggunakan bahasa daerah. Contoh: Rawamangun jangan diubah menjadi Rotterdam Hill karena secara geografis punya nilai yang tidak bisa diubah sembarangan.

Lebih lanjut berdasarkan Peraturan Menteri Dalam Negeri No 39 Tahun 2008, terkait penamaan rupabumi harus menggunakan nama lokal, serta menggunakan Bahasa Indonesia dan/atau Bahasa Daerah. Nama rupabumi yang akurat, konsisten, dan telah dibakukan, akan dikelola dalam Gasetir Nasional. Gasetir Nasional ini penting sebagai kunci utama untuk IG Nasional, Regional dan Global.

Kajian tentang nama tempat seperti topik buku ini disebut toponimi, sedangkan objek kajiannya disebut toponim (nama tempat). Kedua istilah ini berakar dari bahasa Yunani tópos ( Toponimi adalah salah satu dari dua cabang onomastika atau onomatologi, yaitu kajian tentang segala jenis nama diri. Cabang onomastika yang lain adalah antroponimi, yang merupakan kajian tentang nama orang dengan berbagai atributnya, seperti gelar, pangkat, dan lain-lain.

Toponimi merupakan cabang onomastika yang menyelidiki nama tempat. (BRKP) (2003:3) memberikan pengertian toponimi sebagai penamaan unsur geografis yang dapat berupa nama pulau, gunung, bukit, kota, desa. Kajian terkait toponimi tidak dapat dilepaskan dari studi linguistik, antropologi, geografi, sejarah, dan kebudayaan. Dengan kata lain, toponimi merupakan ilmu yang berkaitan dengan penamaan suatu wilayah yang berkaitan dengan kajian linguistik, antropologi, geografi,sejarah, dan kebudayaan.

Hipotesis Sapir-Whorf (dalam Kramch, 2001:11) menyatakan penggunaan bahasa dapat mempengaruhi cara berpikir dan berperilaku. Lebih lanjut, kedua pakar itu mengungkapkan bahwa penamaan merupakan pengaruh dari bahasa, budaya, dan pikiran masyarakat yang bersangkutan. Kramch (2001:11) menjabarkan bahwa teori relativitas linguistik dapat menjadi dasar perumusan hipotesis Sapir-Whorf yang menunjukkan hubungan antara bahasa, budaya, dan pikiran manusia. Sapir-Whorf menyatakan bahwa struktur bahasa bila digunakan secara terus-menerus dapat mempengaruhi cara berpikir dan berperilaku seseorang. Sapir (1921:207) mengungkapkan bahwa bahasa tidak dapat dipisahkan dari budaya dan merupakan warisan sosial yang berbentuk panduan tindakan dan kepercayaan yang menentukan tekstur kehidupan.

Toponimi atau nama tempat merupakan nama yang diberikan kepada unsur rupabumi yang tidak hanya berupa tulisan di peta atau papan nama petunjuk jalan atau lokasi suatu tempat tetapi berupa informasi geospasial yang berfungsi sebagai titik akses langsung dan intuitif terhadap sebuah sumber informasi lainnya.

Toponimi terestrial merupakan kajian nama tempat yang didasarkan pada unsur rupabumi pada suatu tempat berupa informasi geospasial yang difokuskan pada daratan dalam suatu wilayah geografis. Unsur-unsur geografis yang mengacu pada unsur marines atau lautan tidak dideskripsikan lebih lanjut. Hal itu dikarenakan fokus penamaan daratan lebih ditonjolkan dan diberikan pengamatan lebih banyak dibandingkan unsur yang mengandung air atau perairan.

Dalam etnologi, suatu toponimi adalah sebuah nama yang diturunkan dari suatu tempat atau wilayah. Namun sayang, nama daerah di Indonesia kebanyakan sudah di dominasi nama 
asing apalagi di kota-kota besar saat ini. Berubahnnya penggunaan bahasa Indonesia menjadi bahasa asing untuk nama tempat menyebabkan lunturnya budaya bangsa dan tersingkirnya bahasa daerah dan bahasa Indonesia. Padahal, UU RI No. 24 Tahun 2009 tentang bendera, bahasa, lambang negara, serta lagu kebangsaan pada Pasal 36 mengamanatkan bahwa Bahasa Indonesia wajib digunakan dalam nama geografi di Indonesia dan penamaan yang dimaksud dapat menggunakan bahasa daerah.

\section{METODE PENELITIAN}

Penelitian ini dilaksanakan dengan menggunakan metode deskriptif. Sifat penelitian merupakan penggabungan antara penelitian lapangan yang diiringi dengan studi pustaka yang memiliki relevansi dengan penelitian ini. Sumber data dalam penelitian ini memiliki kriteria sebagai berikut: (1) etnik Melayu, (2) memahami budaya dan tata cara adat dan budaya Melayu, (3) berusia antara 20-65 tahun, (4) alat wicara lengkap dan tidak cacat pendengaran, dan (5) pendidikan maksimal SMA sederajat. Penelitian ini menggunakan instrumen pengumpul data sebagai penjaring data. Penjaring data adalah berupa daftar tanyaan terkait toponimi dan etnolinguistik. Daftar tanyaan ini diiringi dengan pertanyaan lepas yang berhubungan toponimi dan etnolinguistik terutama berkaitan dengan penamaan nama kampung atau nama desa. Penjaringan data tersebut disertai perekaman jika diperlukan.

Kajian penelitian ini dalam pelaksanaannya menggunakan metode deskriptif kualitatif. Penggunaan metode deskriptif kualitatif bertujuan untuk mendapatkan gambaran toponimi dan etnolinguistik secara proporsional. Sudaryanto (1993:62) mengungkapkan bahwa penelitian deskriptif dilaksanakan hanya berdasarkan fakta yang ada atau fenomena yang secara empiris hidup di antara para penuturnya yang dihasilkan atau dicatat berupa perian bahasa yang biasa disebut potret. Perian ini tidak menyebutkan benar salahnya penggunaan bahasa oleh para penuturnya.

Penelitian lapangan dan studi kepustakaan ini dilakukan pada bulan Februari 2018--Juni 2018 di Kabupaten Banyuasin. Peneliti mengumpulkan data di lapangan dengan cara wawancara, pengamatan, perekaman, dan dokumentasi. Prosedur pengumpulan data mengacu pada pendapat Moleong (2001) berupa observasi lapangan, wawancara, perekaman, dokumentasi dan studi pustaka. Dalam hal ini, peneliti harus mempersiapkan buku catatan, tape recorder, untuk merekam informasi lisan dari penutur bahasa Minahasa. Samarin (1988:168) mengisyaratkan teknik pemancingan untuk mendapatkan data yang baik dengan dua cara yaitu: (1) pemancingan terjadwal, (2) pemancingan analitis. Pemancingan terjadwal dilakukan karena kekurangtahuan atau ketidaktahuan terhadap data yang ada atau data baru. Pemancingan analitis dilaksanakan karena data yang diambil mengacu pada bidang tertentu dan membutuhkan informasi yang tidak sedikit.

Metode dan teknik analisis data dalam menganalisis penggunaan dan penamaan nama kampung atau nama desa di Kota Manado dengan menggunakan metode deskriptif kualitatif yang disertai pemilahan data dengan menjabarkan pemakaian penamaan nama kampung atau nama desa seperti apa adanya. Hasil temuan yang diperoleh di lapangan dikelompokkan berdasarkan kategori masing-masing. Dengan kata lain, tiap penamaan nama kampung atau nama desa tersebut dideskripsikan sesuai ranahnya masing-masing. Lebih lanjut, dalam pelaksanaannya, kegiatan ini didahului dengan desain survei, pelaksanaan survei, dan pengolahan data hasil survei. Kegiatan yang disurvei antara lain dengan wawancara dengan masyarakat tentang sejarah dan nama dan posisi kampung, konsultasi dengan pejabat setempat, dan pengamatan genesa wilayah serta pengambilan posisi suatu wilayah sebagai data referensi.

Berdasarkan kajian studi pustaka, maka dapat diperoleh data bahwa pembakuan istilah dan nama nama kampung atau nama desa mengacu pada nama generik. Tiap-tiap unsur geografi di Indonesia terdiri dari dua bagian yakni: nama generik yaitu sebutan untuk unsur tersebut dalam bahasa Indonesia atau bahasa lokal/etnis serta nama nama spesifik atau nama diri dari unsur tersebut.

\section{HASIL DAN PEMBAHASAN \\ Sejarah Singkat Pembentukan Kabupaten Banyuasin}

Sumatera Selatan adalah salah satu provinsi di pulau Sumatera yang beribukota Palembang. Luasnya lahan potensial untuk berladang di beberapa tempat dan kekayaan alam di sana menjadi alasan provinsi ini dipilih menjadi tujuan transmigrasi. Hampir seluruh kabupaten/kota memproduksi padi di sawah, 
kecuali Palembang. Berdasarkan data BPS, 70\% daratan di provinsi ini adalah lahan pertanian. Selain itu kesuburan tanahnya sangat cocok dipakai berladang. Salah satu komoditi khas Sumatera Selatan adalah palawija, jagung, ubi jalar, kacang tanah, dan kacang kedelai. Potensi alam yang dimiliki juga sangat besar mulai dari minyak bumi, gas alam, batubara, dan pembangkit tenaga listrik.

Kabupaten Banyuasin merupakan kabupaten pemekaran dari Kabupaten Musi Banyuasin berdasarkan pada pembentukan Kabupaten Banyuasin disahkan dengan UndangUndang Republik Indonesia Nomor 6 Tahun 2002 dan berdasarkan Undang-Undang tersebut maka Menteri Dalam Negeri RI dengan Keputusan Nomor 131.26- 255 Tahun 2002. Berdasarkan keputusan tersebut, Gubernur Sumatera Selatan pada tanggal 14 Agustus 2003 menetapkan Ir. H. Amiruddin Inoed sebagai Pejabat Bupati Banyuasin.

Selanjutnya, setelah melalui proses pemilihan yang demokratis oleh Dewan Perwakilan Rakyat (DPRD) Kabupaten Banyuasin, Ir. H. Amiruddin Inoed terpilih sebagal Bupati definitif Kabupaten Banyuasin Periode 2003--2008.

Pembentukan Kabupaten Banyuasin tersebut diperkuat oleh aspirasi masyarakat Banyuasin untuk meningkatkan kesejahteraan rakyat dan penyelenggaraan pemerintahan dalam melaksanakan pembangunan, serta menjamin pelayanan terhadap rakyat agar kesejahteraan masyarakat terjamin. Kabupaten Banyuasin memiliki 21 kecamatan, 16 kelurahan, dan 288 desa dari 236 kecamatan, 386 kelurahan dari 2.853 di seluruh Sumatera Selatan. Penduduk Kabupaten Banyuasin pada tahun 2017 berjumlah 803.895 jiwa dengan luas wilayah $11.832,99 \mathrm{~km}^{2}$ dan sebaran penduduk $68 \mathrm{jiwa} / \mathrm{km}^{2}$.

\section{Letak Geografis Banyuasin}

Posisi Geografis Kabupaten Banyuasin terletak antara $1,30^{\circ}-4,0^{\circ}$ Lintang Selatan dan $104^{\circ} 00^{\prime}-105^{\circ} 35^{\prime}$ Bujur Timur yang terbentang mulai dan bagian tengah Propinsi Sumatera Selatan sampai dengan bagian Timur dengan luas wilayah seluruhnya $11.832,99 \quad \mathrm{Km}^{2}$ atau 1.183.299 Ha.

Secara geografis Kabupaten Banyuasin berbatasan dengan:

a. Sebelah Utara: Provinsi Jambi, Kabupaten Musi Banyuasin, den Selat Bangka b. Sebelah Selatan: Kabupaten Muara Enim, Kabupaten Ogan Komering Ilir, dan Kota Palembang

c. Sebelah Barat: Kabupaten Musi Banyuasin

d. Sebelah Timur: Selat Bangka dan Kabupaten Ogan Komering Ulu.

Kabupaten Banyuasin beribu kota di Pangkalan Balai yang terletak di Jalur Lintas Timur secara kewilayahan dalam posisi strategis di Provinsi Sumatera Selatan. Kabupaten Banyuasin merupakan daerah penyelenggara pertumbuhan Kota Palembang terutama untuk sektor industri. Di sisi lain bila dikaitkan dengan rencana Kawasan Industri dan pelabuhan Tanjung Api-Api Kabupaten Banyuasin sangat besar peranannya bagi kabupaten di sekitarnya sebagai pusat industri hilir, jasa distribusi produk sumber daya alam baik pertanian, kehutanan, perikanan dan kelautan, dan pertambangan sehingga akan melahirkan kembali kemasyuran Bandar Sriwijaya milik Kabupaten Banyuasin.

Kabupaten Banyuasin memiliki sumber daya alam yang dapat dikelompokkan menjadi sumber daya alam terestrial dan marine. Sumber daya alam terestrial merupakan sumber daya alam yang lokasinya berada di daratan, sedangkan sumber daya alam marine merupakan sumber daya alam yang lokasinya terdapat di perairan.

a. Batubara

Batubara berasal dari endapan hutan karbon jutaan tahun lalu dan mengalami penekanan dan perubahan wujud. Batubara digunakan untuk bahan bakar atau energi di berbagai industri. Endapan batubara banyak ditemukan di Sumatera dan Kalimantan.

b. Emas, intan, dan perak

Emas, intan, dan perak adalah salah satu bahan galian yang bermanfaat untuk perhiasan atau bahan konduktor listrik. Emas dan perak di Indonesia banyak ditemukan di antaranya di Sumatera, Papua, dan Nusa Tenggara. Intan banyak terdapat di Martapura (Kalimantan Selatan).

c. Tembaga

Tembaga adalah bahan galian yang digunakan dalam dunia industri. Tembaga sering digunakan untuk bahan pembuatan kabel atau berbagai macam alat dapur dan lainnya. Tembaga banyak terdapat di Papua.

d. Aspal

Aspal merupakan bahan pelapis jalan raya dan banyak ditemukan di Pulau Buton Sulawesi Tenggara. 
e. Bauksit

Bauksit merupakan bahan dasar logam alumunium. Alumunium sering digunakan untuk rangka pesawat dan alat-alat dapur.

f. Kapur dan Marmer

Kapur adalah bahan galian yang berasal dari koral yang terangkat ke daratan. Kapur banyak digunakan untuk bahan dasar semen. Kapur dapat berubah wujud menjadi batu marmer yang sering digunakan untuk ornamen rumah.

g. Hutan

Hutan menyediakan berbagai macam kebutuhan mulai dari kayu hingga bahan makanan.

h. Hewan ternak

Hewan ternak banyak dibudidayakan di daratan seperti sapi, kambing, bebek, domba, kerbau, kuda, dan hewan sejenisnya.

i. Pertanian

Pertanian yang dilakukan di daratan bervariasi mulai dari padi, palawija, teh, sayuran, hingga buah-buahan.

Sumber daya alam marine

a. Minyak dan gas

Endapan minyak dan gas selain terdapat di daratan, juga banyak muncul di bawah lautan. Kita bisa melihat banyak kilang minyak lepas pantai dibangun. daerah penghasil minyak dan gas di Indonesia di antaranya Bontang, Sorong, Dumai, dan Balongan.

b. Terumbu karang

Terumbu karang banyak terdapat do zona neritik yang masih kaya sinar matahari. Terumbu adalah rumah berbagai macam hewan laut mulai udang, kerang, kuda laut, ikan badut, hingga penyu, dan sejenisnya.

c. Mutiara

Mutiara sering dibudidayakan dengan cara ditanam di dalam kerang. Budidaya mutiara di Indonesia banyak dilakukan di Ambon Maluku.

d. Rumput laut

Rumput laut banyak dibudidayakan di daerah pantai dengan arus tenang seperti pantura. Rumput laut digunakan sebagai bahan dasar makanan, industri kosmetik, dan obat-obatan.

e. Timah

Timah adalah sumber daya alam yang aa di lautan dalam bentuk sedimen. Tambang timah di Indonesia ada di Bangka Belitung. Timah digunakan untuk bahan dasar industri alat rumah tangga hingga untuk bahan konduktor listrik.

\section{f. Ikan laut}

Ikan laut yang bermanfaat bagi manusia di antaranya kakap, tenggiri, sarden, udang, lobster, cumi, sotong, tuna, tongkol, dan sejenisnya.

g. Garam

Garam berasal dari kristalisasi air laut. Tambak-tambak garam di Indonesia banyak terdapat di Pulau Madura.

Berdasarkan temuan data lapangan yang diperoleh di Kabupaten Banyuasin, maka penamaan nama desa di Kabupaten Banyuasin dapat dikelompokkan sebagai berikut.

\section{Nama Desa yang Berasal dari Nama Orang}

Nama desa yang berasal dari nama orang di Kabupaten Banyuasin merujuk pada penggunaan nama atau sebutan atau panggilan orang. Panggilan nama orang tersebut memakai nama gelar yang lazim digunakan sehari-hari bagi panggilan laki-laki atau perempuan. Arti nama desa yang yang berasal dari nama orang memiliki makna yang sebenarnya. Contoh nama desa yang berasal dari nama orang menggunakan nama Sri. Kata Sri memiliki makna gelar kehormatan bagi raja atau orang besar; arti Sri yang lainnya adalah yang mulia: Yang Paduka; Sri Sultan. Kata Sri sering dilekatkan dengan kata berkelas adjektiva dan nomina. Srikaton artinya tanah raja yang terlihat atau diperlihatkan supaya jadi pengingat masyarakat; Sri Mulyo artinya raja yang dimulyakan dengan harapan desa tersebut menjadi mulya bagi pemilik desa yang meninggalinya, orang yang bertempat tinggal di desa tersebut menjadi mulya. Desa Srikaton dan Sri Mulyo terdapat di Kecamatan Air Kumbang. Kata Sri Agung bermakna Paduka raja yang diagungkan atau dihormati. Penamaan Desa Sri Agung oleh penduduk setempat agar masyarakat yang tinggal di desa tersebut memiliki keagungan dan anugerah dari Allah Swt. Desa Sri Agung ini terdapat di Kecamatan Banyuasin II. Penamaan desa Sri Menanti dimaksudkan oleh masyarakatnya agar desa yang ditinggalinya seperti yang diharapkan oleh paduka raja yakni kebahagian, ketentraman, dan keselarasan. Desa Sri Menanti terdapat Kecamatan Tanjung Lago. Penamaan desa Sri Tiga karena merujuk desa ini terletak di antara tiga desa, Penaman desa Sri Jaya oleh masyarakat setempat dimaksudkan agar desa yang ditempatinya memiliki kejayaan seperti yang diharapkan oleh raja, sehingga masyarakat yang bertempat di desa tersebut sejahtera dan memiliki kejayaan. Penamaan desa Sri Bandung mengacu pada penamaan Bandung 
Bondowoso yang memiliki kesaktian luar biasa dan memiliki kelebihan dibandingkan orang biasa. Penamaan desa Sri Kembang dimaksudkan agar desa yang bersangkutan memiliki ketenangan dan kebahagiaan. Kembang identik dengan bunga yang memiliki bau yang harum semerbak. Penamaan desa ini dengan nama Sri Kembang dimaksudkan agar desa tersebut memiliki keharuman dan ketenangan.

$$
\text { Penamaan Desa Damarwulan }
$$

dimaksudkan untuk mengingatkan pada penduduk setempat berasal dari cerita Dawarwulan yang berasal dari Jawa Timur. Hal ini untuk mengingatkan diri mereka berasal dari Jawa Timur. Desa Damarwulan berada di Kecamatan Air Salek. Sedangkan penamaan desa dengan sebutan Kelurahan Mariana dan Kelurahan Mariana Ilir dimaksudkan bahwa dulu desa ini sempat ditinggali orang Belanda yang memiliki anak bernama Mariana. Mariana memiliki kecantikan yang luar biasa. Untuk mengenang kecantikan Mariana, maka masyarakat setempat mengabadikannya untuk menamai desa tersebut. Mariana sampai hari belum diketahui dengan pasti apakah meninggal di Plaju atau Sungai Gerong tempat eksplorasi minyak bumi di Sumatera Selatan pada waktu itu. Plaju dan Sungai Gerong hingga sampai saat ini masih menjadi lokasi pengolahan minyak bumi dan industri perminyakan di wilayah Sumatera Selatan. Kelurahan Mariana dan Kelurahan Mariana Ilir termasuk wilayah Kecamatan Banyuasin I.

Kabupaten Banyuasin secara geografis berbatasan langsung dengan Pulau Bangka Provinsi Bangka Belitung. Selat yang memisahkan wilayah Kabupaten Banyuasin dengan Pulau Bangka adalah Selat Bangka. Selat menurut Kamus Besar Bahasa Indonesia adalah laut di antara pulau-pulau: Selat Malaka; Selat Bangka; makna lainnya adalah sela; celah.

\section{Nama Desa yang Berasal dari Nama Tumbuhan}

Nama desa yang berasal dari nama tumbuh-tumbuhan di Kabupaten Banyuasin adalah Bentayan, Bumi Serdang, Bunga Karang, Manggar Raya, Bengkuang, Biyuku, Durian Daun, Meranti, Kelapa Dua, Ringin Harjo, Kemang Bejalu, Lebung, Pagar Bulan, Penandingan, Sejagung, Semuntur, Limau, Rambutan, Durian Gadis, Gelebak Dalam, Beringin Agung, Cendana, Sebokor, Sebubus, Jatisari, Karangsari, Majuria, Kayuara Kuning, Duren Ijo, Terentang, Terlangu, dan Kelurahan
Kedondong Raye. Penamaan desa dengan mengambil nama tumbuhan atau tanaman bukan tidak ada maksud yang diinginkan oleh masyarakat setempat. Pemberian nama desa dengan menggunakan nama tumbuhan untuk mengabadikan tanaman atau tumbuhan yang hidup di sekitar desa mereka. Hal itu dimaksudkan agar tanaman khas yang dimaksudkan menjadi langgeng dan dikenang selama desa itu masih ditempati atau ditinggali. Dengan demikian, desa tersebut dapat dikenali masyarakat yang hidup di kemudian hari dengan merujuk sejarah desa dan asal usul nama desa yang bersangkutan.

\section{Nama Desa yang Berasal dari Unsur Nama Geografis}

a. Karang

Karang berjenis kata memiliki makna (1) batu kapur di laut yg terjadi dr zat yg dikeluarkan oleh binatang kecil jenis anthozoa (tidak bertulang punggung); batuan organik sbg tempat tinggal binatang karang; koral; (2) pulau (gunung, batu) di laut yg terjadi dr tumpukan karang yg sudah membatu; (3) tumbuhan laut yg menyerupai atau spt karang; selin itu, kata karang mendapat imbuhan pekan akan menjadi bentuk pe.ka.rang.an (berkelas nomina); kata pekarangan ini bermakna (a) tanah sekitar rumah; halaman rumah: tiba-tiba kedengaran suara mobil berhenti di pekarangan rumah; (b) tanah yang disiapkan untuk tempat tinggal: kami sudah mempunyai pekarangan untuk mendirikan rumah; makna lainnya adalah tempat kediaman; tempat berkumpul. Kata pekarangan ini berkelas kata nomina.

Contoh:Karang Anyar, Karang Asem, Karang Mulya, Karang Manunggal.

b. Kebon

Kebon merupakan kata yang berkelas nomina. Kata Kebon sebagai nama geografis di Kabupaten Banyuasin bermakna (1) sebidang tanah yang ditanami pohon musiman (buahbuahan dan sejenisnya); (2) tanah luas yg ditanami kopi, karet, dan sebagainya. Kata kebon bila dihubungkan dengan penamaan desa di Kabupaten Banyuasin adalah Kebon Sahang. Pemberian nama desa dengan Kebon Sahang karena sebelum desa ini terbentuk oleh masyarakat setempat, desa ini merupakan kebun yang ditanami tumbuhan palawija, tanaman kebun tahunan, dan sejenisnya. Namun tanaman tahunan yang ditanam di kebun tersebut adalah tanaman sahang atau 
merica. Kebun tanaman merica yang sangat luas inilah yang menjadi inspirasi masyarakat setempat untuk menamai desa baru yang didirikan dengan mengambil nama tumbuhan yang dominan ditanam di kebun mereka yakni sahang, sehingga masyarakat menamai desa baru mereka dengan Desa Kebon Sahang.

c. Kuala

Kuala merupakan kata yang berkelas kata benda atau nomina. Kata kuala sebagai nama geografis di Kabupaten Banyuasin mempunyai makna (1) tempat pertemuan sungai dengan sungai atau sungai dengan laut; muara sungai; (2) muara bersama-sama dari beberapa aliran menjadi satu. Penamaan desa di Kabupaten Banyuasin yang menggunakan kata kuala adalah Kuala Puntian, Kuala Sugihan. Kuala puntian secara bebas bermakna tempat pertemuan sungai dengan sungai atau dengan laut yang ditempati atau ditinggali oleh sejenis makhluk halus sejenis punti atau lebih sering dikenal dengan kuntilanak atau di pulau kalimantan disebut dengan pontianak. Kuala Sugihan secara umum bermakna tempat pertemuan sungai dengan sungai atau sungai dengan laut; muara sungai yang dikenali dengan beberapa hasil laut yang dapat membuat orang menjadi kaya karena mendapatkan hasil tangkapan yang melimpah seperti ikan yang bernilai komersial sangat mahal, seperti ikan kakap, ikan mata merah, ikan jenis pelagis, kerapu, udang, kerang dan sebagainya.

d. Lalang

Lalang merupakan kata yang berkelas kata benda atau nomina. Lalang sebagai nama geografis di Kabupaten Banyuasin mempunyai makna (1) alang-alang; (2) endapan permukaan yang dihasilkan oleh arus air atau arus udara. Lalang dalam arti ini merujuk pada nama geografis pada endapan tanah pada permukaan karena arus air. Contoh penggunaan kata lalang di wilayah Kabupaten Banyuasin pada Lalang Sembawa. Lalang Sembawa merupakan nama desa yang menggunakan unsur geografis yang ditandai dengan permukaan tanah atau endapan tanah pada permukaan karena arus air atau arus udara yang dibawa oleh air. Wilayah Lalang Sembawa memang ditandai dengan tanah permukaan tanah yang menonjol di sekitaran sungai Sembawa. Penamaan Desa Lalang Sembawa dimaksudkan oleh masyarakatnya agar menjadi pengingat kolektif asal muasal desa di wilayah Kabupaten Banyuasin.

\section{e. Muara}

Muara merupakan kata yang berkelas kata benda atau nomina. Muara sebagai nama geografis di Kabupaten Banyuasin memiliki makna (1) tempat berakhirnya aliran sungai di laut, danau, atau sungai lain; (2) sungai yang dekat dengan laut.

Muara Baru, Muara Sugih, Muara Telang, Muara Telang Marga,

Nusa: Nusa Makmur, Terusan Dalam, Terusan Muara, Terusan Tengah, padang: Padang Rejo, Muara Damai, Muara Abab, Muara Telang, Muara Sugihan, Muara Padang Muara Baru

f. Pulau

Pulau merupakan tanah atau daratan yang dikelilingi air dengan luas lebih kecil dari benua dan lebih besar dari karang yang dikelilingi air. Kata Pulau berkelas kata benda atau nomina. Kumpulan dari beberapa pulau dinamakan pulau-pulau atau kepulauan. Menurut Kamus Besar Bahasa Indonesia, pulau (n) tanah (daratan) yang dikelilingi air (di laut, di sungai, atau di danau); berlayar di pulau kapuk (bahasa percakapan) tidur. Pulau sudah lenyap, daratan sudah tenggelam $\mathrm{pb}$ sudah tidak ada harapan lagi (gagal sama sekali); berlayar menentang (menghadang menuju) pulau, pb setiap usaha harus ada tujuannya;berlayar sampai ke pulau, berlayar sampai ke batas. pb segala usaha hendaklah diselesaikan sampai tercapai maksudnya.

[n] tanah (daratan) yg dikelilingi air (di laut, di sungai, atau di danau) Pulau Karang, Pulau Borang Pulau Harapan, Pulau Muning, Pulau Rajak,

g. Rantau

Rantau merupakan kata berkelas kata benda atau nomina. Rantau bermakna (1) pantai sepanjang teluk (sungai), pesisir (lawan darat); berlayar sepanjang rantau; (2) daerah (negeri) di luar daerah (negeri) sendiri atau daerah (negeri) di luar kampung halaman; negeri asing, teluknya dalam rantaunya sakti pb tidak bisa dikalahkan.

Rantau Bayur, Rantau Harapan

h. Rawa

Rawa merupakan kata yang berkelas kata benda atau nomina. Rawa bermakna tanah yang rendah (umumnya di daerah pantai) dan digenangi air, biasanya banyak terdapat tumbuhan air; berawa (verba) mempunyai 
rawa; terdiri dari rawa; berawa-rawa (verba) banyak rawa, Rawa Banda.

i. Rimba

Rimba merupakan kata yang berkelas kata benda atau nomina. Rimba mempunyai makna (1) hutan lebat (yang luas dengan pohon yang besar-besar); (2)hilang tidak tentu rimbanya, hilang lenyap tanpa meninggalkan kesan atau jejak.

Rimba Raya, Rimba Terab, Rimba Asam, Rimba Alai,

j. Tanah

Tanah merupakan kata yang berkelas kata benda atau nomina. Tanah memiliki makna (1) permukaan bumi atau lapisan bumi yang di atas sekali: hujan membasahi tanah; (2) keadaan bumi di suatu tempat: tanahnya gersang, tidak dapat ditanami; (3) permukaan bumi yang diberi batas: pemerintah menyediakan tanah seluas tiga hektar untuk permukiman para transmigran; (4) daratan: penerjun payung itu tewas setelah jatuh terempas di tanah; (5) permukaan bumi yg terbatas yg ditempati suatu bangsa yg diperintah suatu negara atau menjadi daerah negara; negeri; negara; tanah Eropa; tanah Melayu. Sedangkan kata tanah bila dengan kata arkais yang berkelas kata nomina bermakna satuan ukuran panjang yg sama dengan depa. Kata tanah yang dihubungkan dengan penamaan desa di Kabupaten Banyuasin adalah Tanah Lembak yang bermakna permukaan bumi yang diberi batas dan berada dalam posisi lembab dan mengandung banyak air di sekitarnya.

k. Talang

Pengertian kata talang ${ }^{1} / \mathrm{ta} \cdot \mathrm{lang} / \mathrm{n}$ ikan laut; seliap; Chorinemus lysan merupakan penamaan pada jenis ikan laut yang hidup di perairan dangkal, ikan ini sering dikonsumsi oleh masyarakat pesisir; orang juga sering menyebut ikan talang dengan nama ikan seliap. Nama ikan seliap dalam bahasa latin disebut Chorinemus lysan. Nama latin Chorinemus lysan ikan seliap ini untuk memudahkan klasifikasi, famili, jenis, dan kelas ikan dalam rumpun ilmu biologi.

talang ${ }^{2} /$ ta. lang/ n saluran air (dari buluh, seng, dan sebagainya) pada cucuran atap

Pengertian kata talang $^{2}$ adalah saluran air yang terbuat dari buluh bambu, seng, dan sebagainya yang digunakan pada cucuran atap. Kata talang ${ }^{2}$ ini berkelas nomina atau kata benda. Kata talang ${ }^{2}$ ini sering dipakai dalam lingkungan rumah baik rumah permanen, rumah yang terbuat dari kayu atau rumah yang berdinding bilik bambu. Biasanya orang juga menamai talang $^{2}$ dengan sebutan talang air yang berada di tengah rumah, emperan rumah atau antara rumah induk dengan sambungan rumah lainnya.

talang t $^{3}$.lang/ $n$ perantara dalam jual beli; makelar;

Pengertian kata talang ${ }^{3}$ ini berkelas nomina yang bermakna perantara dalam jual beli atau dikenal dengan sebutan makelar.

talang kuda orang yang menjadi perantara dalam menjual kuda. Perhatikan penggunaan kata talang kuda dalam kalimat berikut. "Pak Daniar merupakan talang kuda Sumba terkenal di daerah ini”. Talang Buluh, Talang Keramat, Talang Kelapa, Talang Lubuk, Talang Kemang, Talang Ipuh, Talang Mainan, Talang Indah,

1. Telang

Kata telang berkelas kata benda atau nomina. Kata telang memiliki makna (1) buluh yang tipis sekali, biasa dipakai untuk memasak lemang dan biasa dianyam menjadi dinding, kata telang ini berkelas kata nomina; (2) (bunga -telang) tumbuhan merambat, daunnya berwarna biru yang berkelas kata nomina; Clitoria ternatea

ber.te.lang-te.lang $\mathrm{v}$ bergaris-garis seperti kulit harimau

Penamaan desa di Kabupaten Banyuasin yang menggunakan kata telang adalah Telang Jaya, Telang Karya, Telang Makmur, Telang Rejo. Makna kata Telang Jaya adalah buluh yang tipis sekali, biasanya dipakai untuk memasak lemang dan biasa dianyam menjadi dinding rumah atau bilik rumah yang memiliki kejayaan bagi penghuninya. Kata telang berkelas kata benda atau nomina. Telang karya adalah buluh yang tipis sekali, biasanya dipakai untuk memasak lemang dan biasa dianyam menjadi dinding rumah atau bilik rumah yang membuat penduduknya selalu rajin untuk bekerja dan berkarya. Telang Makmur buluh yang tipis sekali, biasa dipakai untuk memasak lemang dan biasa dianyam menjadi dinding rumah dan penghuni rumah atau penghuni desa akan mendapatkan kemakmuran sepertu yang diharapakan. Sedangkan Telang Rejo bermakna buluh yang tipis sekali, biasa dipakai untuk memasak lemang dan biasa dianyam menjadi dinding rumah dan diharapkan penghuni desa menjadi 
sejahtera dan bahagia karena berkecukupan sandang pangannya.

m. Sungai

Sungai berkelas kata benda atau nomina. Sungai sebagai nama geografis di Kabupaten Banyuasin adalah Sungai Rengit, Sungai Rengit Murni, Sungai Lilin, Sungai Pinang, Sungai Naik, Sungai Dua, Sungai Kedukan, Sungai Pinang, Sungai Gerong, Sungai Rebo, Sungai Semut Pengertian sungai menurut KBBI IV adalah 1. aliran air yg besar (biasanya buatan alam); kali: sungai atau kali itu dapat dilayari sampai ke pedalaman; sungai atau kali bawah tanah aliran air yang mengalir melalui ruang-antara yang sangat besar, seperti gua yang bersambungan; sungai permukaan yg menghilang ke bawah tanah, seperti melalui lubang terlangah dan yg memasuki aliran bawah tanah; sungai malar (bidang Hidrologi) sungai yg mengalir terusmenerus sepanjang tahun; sungai menahun sungai malar; sungai merugi (Hidrologi) sungai yang menyumbangkan air ke air tanah melalui peresapan; ke sungai bermakna menuju sungai; 2 cak buang air besar (biasanya di sungai); ke sungai bermakna sembari atau sambil mandi, peribahasa sekali bekerja dua tiga pekerjaan terselesaikan

n. Upang

Upang menurut penuturan orang setempat bermakna tanah yang berada di tiga persimpangan sungai yang menuju ke muara. Tanah tersebut ditanami tanaman hutan ataupun tanaman padi atau palawija. Orang sekitaran muara di Kabupaten Banyuasin bila ditanya akan kemana sepagi ini, maka orang akan menjawab akan pergi ke upang sebelah sungai sebelah misalnya, karena lahan kebun miliknya berada di sebelah sungai yang biasa dilewati. Pengertian kedua terkait upang adalah nama orang yang memiliki tanah di sekitaran muara. Bapak Upang sudah lama meninggal, namun orang di sekitaran sungai dan muara telanjur menyebut ke muara dengan sebuutan pergi ke upang. Untuk membuktikan kebenaran ini, tentu memerlukan kajian lebih lanjut. Penggunaan kata upang sebagai nama geografis di Kabupaten Banyuasin adalah: Upang Cemara, Upang Ceria, Upang Jaya, Upang Karya, Upang, Upang Marga Upang Makmur, Upang Mulya, Delta Upang. o. Tebing

Tebing berkelas kata benda atau nomina. Tebing sebagai nama geografis di Kabupaten Banyuasin mempunyai makna (1) tepi sungai (jurang) yg tinggi dan terjal (hampir tegak): sungai itu tinggi tebingnya; banyak tanah di tebing sungai itu longsor; (2) lereng gunung (bukit) seperti dinding terjal: tebing gunung; (3) tepi tanah darat yang tinggi dan terjal sebagai pemisah dari rawa, sawah, yang ada di samping bawahnya. Penamaan desa dengan kata tebing sebagai nama geografis di Kabupaten Banyuasin adalah Tebing Abang. Tebing Abang bermakna tepi sungai (jurang) yang tinggi dan terjal (hampir tegak), tebing itu berwarna merah bata, sehingga masyarakat setempat menyebutnya Tebing Abang.

p. Teluk

Teluk berkelas kata benda atau nomina. Teluk sebagai nama geografis di Kabupaten Banyuasin memiliki makna (1) bagian laut yang menjorok ke darat; (2) keluk (di pantai); sedangkan teluk sebagai bentuk kata arkhais termasuk kelas kata kerja atau verba seperti contoh pada kata ber.te.luk; berlutut; bertelut. Penggunaan kata teluk di Kabupaten Banyuasin adalah Teluk Tenggirik, Teluk Tenggulang (Kecamatan Tungkal Ilir), Teluk Betung, Teluk Payo.

q. Nama Desa yang Berasal dari Nama Tanjung Kata Tanjung berkelas kata benda atau nomina. Kata tanjung sebagai nama geografis di Kabupaten Banyuasin memiliki makna (1) Definisi kata 'tanjung' dalam bahasa Indonesia bermakna tanah (hujung) atau pegunungan yang menganjur ke laut (ke danau). Kata tanjung dalam pengertian ini merupakan kata berkelas kata benda atau berkelas nomina. Kata tanjung berkelas nomina ini dapat menjadi kata yang berkelas verba/kata kerja setelah mendapat penambahan afiks me+tanjung sehingga menjadi menanjung yang bermakna kelihatan sebagai tanjung; menganjur ke laut seperti tanjung; dan pengertian yang lain adalah berlayar sepanjang atau menyusur tanjung. Kata tanjung ini pun memiliki makna pohon yang bunganya berwarna putih kekuning-kuningan dan berbau harum, biasa dipakai untuk hiasan sanggul dengan sebutan latin adalah Mimusops elengi. Pengertian kata tanjung lainnya merupakan tumbuhan paku yang tumbuh di rawa-rawa yang disebut dalam bahasa latin Diplazium esculentum. 
Pengertian kata tanjung yang terakhir bermakna bintang perak atau emas tanda pangkat (disematkan pada polet atau leher baju (http://artikata.com/arti-353294Tanjung.html). Kata tanjung bila dihubungkan dengan nama geografis di Kabupaten Banyuasin adalah Desa Tanjung Lago (nama kecamatan juga), Tanjung Laut, Tanjung Menang Musi, Tanjung Pasir, Tanjung Tiga, Tanjung Kerang, Tanjung Merbu, Tanjung Agung, Tanjung Beringin, Tanjung Kepayang, Tanjung Menang, Tanjung Baru, Tanjung Mas, Ujung Tanjung.

r. Nama Desa yang Berasal dari Nama Pematang Penamaan desa dengan menggunakan nama geografis di Kabupaten Banyuasin adalah Pematang Palas. Pematang adalah berarti jalan kecil yang ditinggikan biasanya berada di sawah. Pematang Palas secara umum bermakna jalan kecil yang ditinggikan biasanya berada di sawah yang ditandai dengan rerumputan yang dijadikan alas untuk jalan setapak di pematang.

s. Nama Desa yang Berhubungan dengan Kata Pangkalan

Nama desa yang berhubungan dengan kata pangkalan sebagai nama geografis di Kabupaten Banyuasin adalah (1) pangkalan memiliki arti $n$ tempat kapal atau perahu berlabuh; tepi laut (atau tepi sungai) tempat berlabuh; (2) $n$ tempat menimbun (mengumpulkan) barang-barang dagangan, hasil bumi, dan sebagainya; (3) $n$ tempat (pelabuhan, lapangan terbang, dan sebagainya) yang dijadikan tumpuan untuk menyerang musuh; (4) $n$ tempat tertentu untuk berkedai, menjual material atau bahan bangunan, perhentian taksi, dan sebagainya; (5) $n M k$ tuan atau nyonya rumah (penerima tamu): si pangkalan. https://kbbi.kemdikbud. go.id/entri/pangkalan

Contoh kata nama geografis yang menggunakan kata pangkalan di Kabupaten Banyuasin adalah Pangkalan Benteng, , Pangkalan Gelebak, Pangkalan Panji, Pangkalan Balai.

t. Nama Desa yang Menggunakan Kata Lubuk Lubuk merupakan kata yang berkelas kata benda atau nomina. Lubuk sebagai nama geografis di Kabupaten Banyuasin memiliki makna (1) bagian yang dalam di sungai (laut, danau, dan sebagainya)seperti menangkap ikan di lubuk (nomina); dengan kata lain lubuk berati bagian terdalam di sungai atau cekungan dalam di dasar sungai (2) berlekuk dalam; jeluk: piring lubuk; pinggan lubuk; (3) daerah hidrosfer yang kedalamannya dapat mencapai 6.000 kaki atau lebih di lautan dan 1.000 kaki atau lebih di danau dan yg tidak tertembus oleh cahaya matahari. Kata lubuk yang digunakan di wilayah geografis Kabupaten Banyuasin adalah Lubuk Saung dan Lubuk Karet. Kata Lubuk Saung memiliki makna bagian yang dalam di sungai yang ditandai adanya gubuk atau dangau untuk istirahat dari panas dan hujan di pinggiran lubuk sungai. Lubuk Karet memiliki makna bagian yang dalam di sungai yang ditandai dengan hamparan tanaman karet di sekitaran lubuk. Selain itu terdapat kata Lubuk Rancang dan Lubuk Rengas.

u. Nama Desa yang Berhubungan dengan Harapan Merupakan Penamaan Desa yang Mengacu pada Bentuk atau Wujud Desa yang Berhubungan dengan Harapan

Penamaan desa dengan menggunakan nama geografis dengan memberi nama yang berhubungan dengan harapan di Kabupaten Banyuasin dapat ditunjukkan pada contoh nama desa di Kabupaten Banyuasin sebagai berikut.

Desa sukadamai nama desa yang mengacu pada kesukaan masyarakat desa untuk menjadi desa yang damai dan tenang.

Contoh: Desa Panca Mulya, Sido Mulyo, Suka Karya, Suka Raja, Suka Jaya, Suka Mulya di Kecamatan Tungkal Ilir; Desa Mulya Sari, Suka Damai, Suka Tani, Sumber Mekar Mukti di Kecamatan Tanjung Lago; Sukajadi, Sukomoro di Kecamatan Talang Kelapa; Desa Sumber Jaya di Kecamatan Sumber Marga Telang; Suka Raja di Kecamatan Suak Tapeh; Rejo Bumi, Mekar Sari, Purwodadi, Songo Makmur, Sumber Agung, Sumber Mukti, Sumber Rejo, Wonodadi di Kecamatan Selat Penuguan; Desa Purwosari, Rejodadi, Sako Makmur, Santan Sari di Kecamatan Sembawa; Budi Asih, Dana Mulya, Nunggal Sari, Rukun Makmur, Senda Mukti, Sumber Mulyo, Sumber Rejeki, Tirta Mulya, Wana Mukti, Wonosari di Kecamatan Pulau Rimau; Marga Rahayu, Mekar Mukti, Mekar Sari, Mukti Jaya, Panca Mukti, Sumber Hidup, Sumber Mulya di Kecamatan Muara Telang; Desa Argo Mulyo, Jalur Mulya, Marga Rukun, Margo Mulyo 16, Mekar Jaya, Rejosari, Sido Makmur, Sugih Waras, Sumber Mulyo. 
Timbul Jaya, Tirto Mulyo, Tirto Harjo di Kecamatan Muara Sugihan; Desa Purwodadi, Sidomulyo 18, Sidomulyo 20, Sidorejo, Sumber Makmur, Tanjung Baru, Tirta Jaya, Tirta Raharja, Margomulyo, Karanganyar di Kecamatan Muara Padang; Desa Pendowoharjo, Pangestu, Purwosari, Tirta Kencana di Kecamatan Makarti Jaya; Desa Suka Mulya Kecamatan Betung; Desa Suka Mulya, Sukaraja, Sukaraja Baru di Kecamatan Banyuasin III; Desa Mekarsari, Sumber Rejeki di Kecamatan Banyuasin II; Desa Tirto Sari di Kecamatan Banyuasin; Desa Enggal Rejo, Sidoharjo di Kecamatan Air Salek; Desa Budi Mulya, Panca Desa, Panca Mulya, Sido Makmur, Sidomulyo, dan Tirto Makmur di Kecamatan Air Kumbang; Marga Rahayu (Kecamatan Tungkal Ilir). Telang Sari (Tanjung Lago); Karang Anyar, Karang Baru, Purwosari, Suka Pindah, Sukarela, Daya Bangun Harjo, Daya Kesuma, Daya Murni, Ganesha Mukti, Gilirang, Indrapura, Mulya Agung Makarti Jaya.

Berdasarkan data yang ada, apabila ditelusuri lebih jauh sepertinya, nama-nama desa yang ada memiliki kecenderungan nama-nama yang terdapat dalam kosakata bahasa Jawa. Apakah karena penduduk setempat yang berasal dari Jawa karena adanya program transmigrasi ataukah karena orang Jawa yang datang secara perorangan ke Sumatera Selatan. Ini perlu ditelusuri lebih lanjut, sehingga data yang diperoleh nantinya dapat dipertanggungjawabkan secara nyata dan konkret. Menurut Wakil Gubernur Ishak Mekki saat berbicara pada saat pembukaan seminar ketransmigrasian dengan tema Revitalisasi Transmigrasi Indonesia "selasa' 12/11 di Program Pascasarjana Universitas Sriwijaya, mengatakan sejak 1969/1970 sampai saat ini tidak kurang terdapat hampir 1 juta jiwa penduduk Sumsel yang berasal dari transmigran. Para transmigran hidup dan tinggal di Sumatera Selatan yang bermukim di 629 unit pemukiman transmigran UPT yang tersebar di 11 kabupaten dan 4 kota di Sumatera Selatan. (November 2013)

\section{PENUTUP}

Berdasarkan paparan pada bab sebelumnya, maka hasil kajian ini dapat diambil simpulan sebagai berikut.

Penamaan desa di Kabupaten Banyuasin berdasarkan persepsi toponimi terestrial mengacu pada sumber daya alam terestrial dan sumber daya marine (maritim). Penamaan desa cenderung mengacu pada (1) nama desa yang berasal dari nama orang; (2) nama desa yang berasal dari nama tumbuhan; (3) nama desa yang berasal dari unsur nama geografis a) karang, b) kebon, c) kuala, d) lalang, e) muara, f) pulau, g) rantau, h) rawa, i) rimba, j) tanah, k) talang, l) telang, $\mathrm{m}$ ) sungai, n)upang, o) tebing, p) teluk, q) nama yang berasal dari nama tanjung, r) nama desa yang berasal dari nama pematang, s) nama desa yang berhubungan dengan pangkalan, t) nama desa yang menggunakan kata lubuk, u) nama desa yang berhubungan dengan harapan merupakan penamaan desa yang mengacu pada bentuk atau wujud desa yang berhubungan dengan harapan.

\section{DAFTAR PUSTAKA}

Alwi, Hasan, dkk. 2003. Tata Bahasa Baku Bahasa Indonesia. Edisi ketiga. Jakarta: Balai Pustaka. dkk. (2005). Kamus Besar Bahasa Indonesia Edisi Ketiga. Jakarta: Balai Pustaka.

Kosasih, Dede. (2010). "Kosmologi Sistem Nama Diri (Antroponim) Masyarakat Sunda". Seminar Internasional Hari Bahasa Ibu, hlm. 33--38.

Kridalaksana, Harimurti. (2007). Pembentukan Kata dalam bahasa Indonesia. Jakarta: Gramedia.

Moleong, Lexy. J. (2010). Metodologi Penelitian Kualitatif. Bandung: Remaja Rosda Karya.

Ramlan. (2001). Morfologi Suatu Tinjauan Deskriptif. Yogyakarta: Karyono.

Ristanto. 2019. Asal dan Makna Nama Desa di Kabupaten Tanjungjabung Barat. artikel Jurnal Mlangun Volume 16 Nomor 2, Desember 2019, halaman 147-162.

Samarin, William J. (1988). Ilmu Bahasa Lapangan. Yogyakarta: Kanisius.

Sudaryanto. (1988). Metode Linguistik Bagian Pertama ke Arah Memahami Metode Linguistik. Yogyakarta: Gajah Mada University Press.

(1993). Metode dan Aneka Teknik Analisis Bahasa. Yogyakarta: DutaWacana University Press. 
Sudaryat, Yayat dkk. (2009). Toponimi Jawa Barat (Berdasarkan Cerita Rakyat). Bandung: Dinas Pariwisata dan Kebudayaan Propinsi Jawa Barat.

Widodo, Ridho. (2001). "Nama Diri Etnik Jawa". Humaniora, 1, XII, hlm. 45--55. 
Volume 5 No. 2 METALINGUA

Oktober 2020 Jurnal Pendidikan Bahasa dan Sastra Indonesia 